\title{
SOEP
}

SOEPpapers
on Multidisciplinary Panel Data Research

SOEPpapers
on Multidisciplinary Panel Data Research

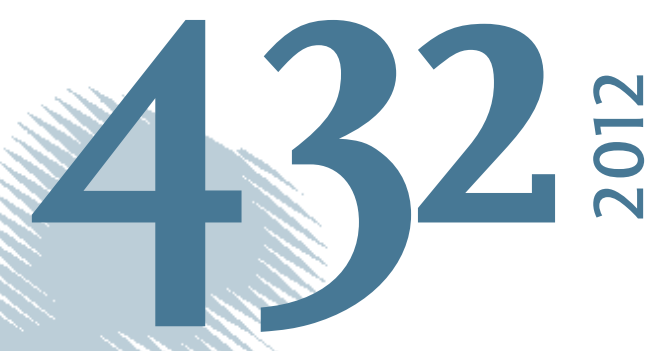

\section{Does job loss make you smoke and gain weight?}




\section{SOEPpapers on Multidisciplinary Panel Data Research}

at DIW Berlin

This series presents research findings based either directly on data from the German SocioEconomic Panel Study (SOEP) or using SOEP data as part of an internationally comparable data set (e.g. CNEF, ECHP, LIS, LWS, CHER/PACO). SOEP is a truly multidisciplinary household panel study covering a wide range of social and behavioral sciences: economics, sociology, psychology, survey methodology, econometrics and applied statistics, educational science, political science, public health, behavioral genetics, demography, geography, and sport science.

The decision to publish a submission in SOEPpapers is made by a board of editors chosen by the DIW Berlin to represent the wide range of disciplines covered by SOEP. There is no external referee process and papers are either accepted or rejected without revision. Papers appear in this series as works in progress and may also appear elsewhere. They often represent preliminary studies and are circulated to encourage discussion. Citation of such a paper should account for its provisional character. A revised version may be requested from the author directly.

Any opinions expressed in this series are those of the author(s) and not those of DIW Berlin. Research disseminated by DIW Berlin may include views on public policy issues, but the institute itself takes no institutional policy positions.

The SOEPpapers are available at

http://www.diw.de/soeppapers

\section{Editors:}

Jürgen Schupp (Sociology, Vice Dean DIW Graduate Center)

Gert G. Wagner (Social Sciences)

Conchita D'Ambrosio (Public Economics)

Denis Gerstorf (Psychology, DIW Research Professor)

Elke Holst (Gender Studies)

Frauke Kreuter (Survey Methodology, DIW Research Professor)

Martin Kroh (Political Science and Survey Methodology)

Frieder R. Lang (Psychology, DIW Research Professor)

Henning Lohmann (Sociology, DIW Research Professor)

Jörg-Peter Schräpler (Survey Methodology, DIW Research Professor)

Thomas Siedler (Empirical Economics)

C. Katharina Spieß (Empirical Economics and Educational Science)

ISSN: 1864-6689 (online)

German Socio-Economic Panel Study (SOEP)

DIW Berlin

Mohrenstrasse 58

10117 Berlin, Germany

Contact: Uta Rahmann | soeppapers@diw.de 


\title{
Does job loss make you smoke and gain weight?
}

\author{
Jan Marcus ${ }^{1}$ (DIW Berlin)
}

This paper estimates the effect of involuntary job loss on smoking behavior and body weight using German Socio-Economic Panel Study data. Baseline nonsmokers are more likely to start smoking due to job loss, while smokers do not intensify their smoking. Job loss increases body weight slightly, but significantly. In particular, single individuals as well as those with lower health or socioeconomic status prior to job loss exhibit high rates of smoking initiation. The applied regression-adjusted semiparametric difference-indifference matching strategy is robust against selection on observables and time-invariant unobservables. This paper provides an indirect test showing that the identifying assumption is not violated in the difference-in-difference estimator. The findings are robust over various matching specifications and different choices of the conditioning variables.

JEL: I12, J65

Keywords: Job loss, smoking, body weight, health behavior, difference-indifference, propensity score matching

\footnotetext{
${ }^{1}$ Jan Marcus, Mohrenstraße 58, DIW Berlin, 10117 Berlin, Germany; jmarcus@diw.de. Valuable comments by Lex Borghans, Adam Lederer, Mathis Schröder, Thomas Siedler, Martin Simmler, Carla Welch and Nicolas Ziebarth are gratefully acknowledged. I would also like to thank seminar participants at DIW Berlin and the Warsaw International Economic Meeting.
} 


\section{Introduction}

The loss of employment has a deep impact on the individual affected. It not only reduces income in both the short and long run (Jacobson et al. 1993), it also results in a plethora of other negative issues, such as decreased life-satisfaction (Kassenboehmer \& HaiskenDeNew 2009), increased risk of divorce (Charles \& Stephens 2004) and further job losses (Stevens 1997) as well as negative consequences for the children of those affected (Lindo 2011). This paper contributes to the literature on the effects of job loss by looking at the impact of involuntary job loss on smoking behavior and body weight. Knowing more about the overall consequences of job loss is crucial - especially in times of financial and economic crises. Furthermore, analyzing the effects of job loss on health behaviors may help us to better understand two recent economic findings: Why job loss increases mortality on the individual level (Eliason \& Storrie 2009; Sullivan \& Wachter 2009) and why - at an aggregated level - health behaviors improve when the unemployment rate is high (Ruhm \& Black 2002; Ruhm 2005).

There is ample evidence that unemployed individuals engage in unhealthy behaviors more often than those in employment (see Henkel 2011; Roelfs et al. 2011). However, it is unclear whether this represents the causal effect of unemployment, the reverse causal effect or a spurious correlation. Most studies on the effect of job loss on health behaviors suffer from various shortcomings. The studies focus on correlations, concentrate on case-studies, do not deal with the endogeneity of job loss, or do not draw on longitudinal data (see Roelfs et al. 2011). This paper addresses these shortcomings by reverting to population-representative survey data, by looking at involuntary job loss, and by applying a regression-adjusted semiparametric difference-in-difference matching strategy. This strategy is not only robust against selection on observables (as conventional matching estimators), but also against selection on time-invariant unobservables (e.g., ability, childhood conditions). To interpret the estimated effects as causal effects, the estimation strategy assumes that no unobservable variables exist that simultaneously influence the probability of job loss and changes in health behaviors. This paper provides an indirect test to show that this identifying assumption is not violated in the present case.

Empirical evidence on the effects of job loss on health behaviors is mixed, although most studies find that job loss changes health behaviors for the worse (see Henkel 2011; Roelfs et al. 2011). It seems likely that these contradictory findings are at least partially due to methodological weaknesses. Only a few studies rely on longitudinal data and simultaneously do not concentrate on single plants. Among these studies, Morris et al. 
(1992) find job loss-related increases in body weight but no increases in either smoking or drinking. Another British study (Montgomery et al. 1998) finds an increased risk of smoking and low body weight among male participants with experience of unemployment - even when controlling for health behaviors at age 16.

Two studies using the U.S. Health and Retirement Survey (HRS) provide the most sophisticated strategies for the identification of causal effects, as they rely on longitudinal data and focus on involuntary job loss. Falba et al. (2005) show that job loss increases the probability of smoking relapse and increases the daily number of cigarettes smoked by existing smokers. Deb et al. (2011) find an increase in drinking and in the probability of being overweight, but only for individuals who already had poor health behaviors prior to job loss. This paper supplements these two studies by applying a different estimation technique, and by looking at the effect of job loss in a different welfare regime. While Falba et al. (2005) apply logit/OLS regressions and Deb et al. (2011) finite mixture models, this paper resorts to matching, an intuitive approach that does not rely as much on linearity assumptions. Due to the HRS sampling design these two studies can only look at individuals over 50, while the data of the German Socio-Economic Panel Study (SOEP) allows for an analysis of the entire range of working-age individuals. It is interesting to determine whether the patterns found for the U.S. also emerge for a country under a different welfare regime. By focusing on Germany this paper looks at a country with more generous unemployment assistance than the U.S.

Using German survey data (SOEP) for 2002-2010, this paper finds that job loss increases the probability of smoking initiation by 3 percentage points ( 56 percent) on average. However, there is little evidence that baseline smokers, i.e. individuals who smoked before the job loss, intensify their smoking or are less likely to stop smoking due to job loss. Job loss increases body weight slightly (by around $0.3 \mathrm{~kg}$ ), but significantly. These findings emerge regardless as to whether only those individuals who lost their jobs due to plant closure are considered, or all individuals experiencing job loss due either to plant closure or dismissal. The results are robust over various matching specifications and different choices of the conditioning variables. Further analyses indicate treatment effect heterogeneity. In particular, single individuals as well as individuals with lower health or socioeconomic status prior to job loss exhibit high rates of smoking initiation. The increase in body weight is significantly larger for women and overweight individuals, but still below one kilogram. In general, the effects on smoking and body weight are smaller than comparable findings for the U.S., which might be attributable to the more generous unemployment assistance in Germany. 
The paper proceeds as follows. The next section briefly summarizes related literature. Section 3 describes in more detail the general idea of the estimation strategy, its implementation and its advantages. Section 4 introduces the data; section 5 compares the distribution of relevant variables before and after matching and, hence, assesses the matching quality. Section 6 presents the results and section 7 examines the robustness of these results with respect to different model specifications. While the previous sections focus on average effects, section 8 looks at the heterogeneity of the effects. Section 9 concludes.

\section{Related Literature}

Initially the economic literature on the impact of job loss focused on lost earnings (see e.g. Jacobson et al. 1993). Research in the field developed and started looking at the implications of job loss beyond mere financial consequences to acquire a more exhaustive picture of job loss. This is of particular importance in times of financial and economic crises, but is also of wider relevance.

Previous research finds that the loss of employment strongly reduces life satisfaction (Kassenboehmer \& Haisken-DeNew 2009), increases the risk of divorce (Charles \& Stephens 2004) and decreases fertility (Del Bono et al. 2012). Other studies analyze the health consequences of job loss. Unemployed individuals experience higher mortality (see Roelfs et al. 2011) and several studies provide evidence that this is (partially) due to the loss of employment and not merely due to poorer health status or other observable factors prior to job loss (Eliason \& Storrie 2009; Sullivan \& Wachter 2009). ${ }^{2}$

At the macro-level, however, increases in the unemployment rate are found to reduce mortality (Ruhm 2000). While infant health also improves at aggregated levels when unemployment is high (Dehejia \& Lleras-Muney 2004), on the individual level the loss of employment is found to reduce the birth weight of own children (Lindo 2011). Furthermore, physical inactivity and body weight as well as tobacco and alcohol consumption decrease during economic downturns (Ruhm \& Black 2002; Ruhm 2005). However, it is not clear whether the improvement in health behavior is driven by the unemployed or by those individuals who are still in employment but working less.

\footnotetext{
${ }^{2}$ However, there are other studies with sophisticated identification strategies that do not find significant adverse health effects of job loss (Browning et al. 2006; Böckerman \& Ilmakunnas 2009; Salm 2009; Schmitz 2011). These studies look at morbidity and health status indicators rather than at mortality. Kuhn et al. (2009) find increases in public health costs, resulting from job loss, predominantly for the treatment of mental health problems.
} 
The literature discusses several arguments as to why job loss might affect smoking and body weight. From a theoretical point of view it is not clear whether job loss improves or worsens health behaviors. ${ }^{3}$ One of the most relevant mechanisms might be stress. Medical studies find that stress increases both eating (Adam \& Epel 2007) and smoking (Kassel et al. 2003). Hence, to cope with the stress associated with job loss, individuals might increase calorie and nicotine intake as a form of self-medication. Job loss-related stress might result from the fear of not finding a new job, reduced income and the loss of the non-financial benefits of work, such as respect of others, adhering to social norms and, therefore, identity (Akerlof \& Kranton 2000).

Job loss might also affect health behaviors through an income effect. The loss in income might reduce the number of cigarettes smoked. The income effect on body weight is ambiguous (consumption of less food vs. cheaper, less healthy food). However, unemployment benefits are comparably generous in Germany. Recipients get $60 \%$ of their previous income (or $67 \%$ if they have a child) for up to 24 months, depending on the duration of their own contributions to unemployment insurance. Moreover, the unemployed can receive tax-financed unemployment assistance, if unemployment insurance payments are below a certain threshold or if the payment period expires (see Caliendo et al. 2009). Other arguments as to why job loss might affect smoking and body weight include increased leisure time (with ambiguous effects on health behaviors) and a shift in the individual's time preference towards the present (Schunck \& Rogge 2010).

Research on the impact of job loss on health behaviors contributes to the literature in several ways. Firstly, it investigates one of the potential mechanisms as to why job loss increases mortality. Job loss might have negative health consequences if health behaviors deteriorate. Secondly, analyzing the effect of job loss on smoking and body weight deepens our understanding of why aggregated health behaviors improve during economic downturns. Thirdly, the effect of job loss on health behavior is also relevant from a public health perspective. Smoking and excess body weight are first and third among the major causes of preventable deaths in industrialized countries according to the World Health Organization (2009). ${ }^{4}$ Policies aimed at reducing the prevalence of smoking and being overweight may be more effective if they consider the vulnerability of specific groups, such as individuals who have lost their employment.

\footnotetext{
${ }^{3}$ In a strict sense, body weight is a state rather than a behavior. Yet, for the purpose of this study, body weight is considered to be a health behavior as it actually combines two health behaviors, eating (calories in) and exercising (calories out).

${ }^{4}$ Comparable studies produce similar results regarding the dangers of smoking and excess weight (see Cawley \& Ruhm 2011).
} 


\section{Empirical Strategy}

To investigate the causal effect of job loss on body weight, smoking status and the daily number of cigarettes smoked, this paper applies a regression-adjusted differencein-difference (DiD) matching strategy, similar to the one proposed by Heckman et al. (1997). The general idea of this estimator is to compare individuals who have lost their jobs with (nearly identical) individuals who have not lost their jobs and to see how the health behaviors of these two groups changed. This study focuses on the average treatment effect on the treated (ATT), i.e. change in health behaviors brought about by the job loss of those who actually lost their employment. The identifying assumption for this ATT is that no unobserved variables exist that determine job loss and simultaneously influence a change in health behaviors, i.e. in the absence of treatment (job loss) the health behaviors of treated (individuals experiencing job loss) and matched controls (similar individuals not experiencing job loss in the period) follows the same trend. In formal notation the identifying assumption is given as:

$$
E_{P \mid D=1} E\left[Y_{0}^{a}-Y_{0}^{b} \mid P, D=1\right]=E_{P \mid D=1} E\left[Y_{0}^{a}-Y_{0}^{b} \mid P, D=0\right],
$$

where $\Delta Y_{0}=Y_{0}^{a}-Y_{0}^{b}$ refers to the change in health behaviors from before $(b)$ to after $(a)$ the treatment in the absence of treatment and $D$ denotes the treatment group indicator. $P$, the propensity score, is the conditional probability of job loss, i.e. $P=P\left(D=1 \mid S^{b}\right)$, where $S^{b}$ is a set of conditioning variables obtained in the pre-treatment period.

In general, DiD matching estimators of the ATT can be written as (Heckman et al. 1997; Smith \& Todd 2005):

$$
\widehat{A T T}=\frac{1}{n_{1}} \sum_{i \in I_{1}}\left[\Delta Y_{1 i}-\sum_{j \in I_{0}} \omega(i, j) \cdot \Delta Y_{0 j}\right]
$$

where $n_{1}$ is the number of cases in the treatment group $I_{1}$. $I_{0}$ indicates the control group observations and $\omega(i, j)$ is a matching procedure specific weight. For instance, for $k$ nearest neighbor matching the weights $\omega(i, j)$ take on the value $1 / k$ for the $k$ nearest control neighbors of each treated $i$ and 0 for all other non-treated. The ATT can be also expressed in matrix notation as:

$$
\widehat{\beta}=\left(\mathbf{X}^{\prime} \mathbf{W X}\right)^{-1} \mathbf{X}^{\prime} \Delta y
$$

where $\Delta y$ is the vector of health behavior changes and $\mathbf{W}$ a diagonal matrix with 1 in 
the $z$-by-zth place for individuals of the treatment group and $\omega(j)=\sum_{i \in I_{1}} \omega(i, j)$ in the $z$-by-zth place for control group members. In the case of matching without regression adjustment, $\mathbf{X}$ is a $n$-by-2 matrix, in which the first column consists of a vector of $1 \mathrm{~s}$ and the second column of the values of $\mathrm{D}$ for each individual. With regression adjustment $\mathbf{X}$ contains an additional column for each adjustment variable. ${ }^{5}$

I apply a three-step procedure to estimate the ATT. First, I estimate the propensity score, then I compute the weighting matrix of equation (3) and finally I perform a weighted regression to compute the ATT. In the first step, I estimate the propensity score by Probit regressions on the pooled sample. I do not revert to the propensity score directly but instead use the linear index of the propensity score, which is particularly effective at improving the balance between treated and controls (Rosenbaum \& Rubin 1985a). In order to prevent the comparison of treated and untreated that are not comparable, I restrict the analysis to the region of common support. The analysis excludes treated observations whose linear propensity score exceeds the maximum of the linear propensity score in the control group or falls below its minimum. For kernel matching, the Epanechnikov kernel works as an additional common support condition since it matches only control observations within a specific interval around each treated observation.

In the second step, I compute the weights within cells defined by baseline smoking status (yes/no) and survey year according to the distance in the linear propensity score. ${ }^{6}$ This is equivalent to exact matching on survey year and smoking status. As equations (2) and (3) show matching procedures basically differ with respect to the weights. ${ }^{7}$ Asymptotically, all matching procedures should produce the same results because they reduce to exact matching in infinite samples (Caliendo \& Kopeinig 2008). For finite

\footnotetext{
${ }^{5}$ Morgan \& Harding (2006) use a similar notation for introducing propensity score weighting (PSW). PSW differs notationally only with respect to the construction of W. For each control group member $j$ the diagonal element of $\mathbf{W}$ equals $\omega(j)=\widehat{P_{j}}\left(1-\widehat{P_{j}}\right)$. Hence, $\omega(j)$ is purely a function of the estimated propensity score, $\widehat{P}_{j}$, and not of the distance to any treatment observation. PSW asymptotically yields the same estimate as the mean difference between treated and matched controls. The matching estimator presented here, however, yields (in the absence of regression adjustment) numerically identical ATT estimates as the mean difference between treated and matched controls because this weighting method is basically a rewriting exercise. PSW is sensitive to misspecification of the propensity score equation because the propensity score enters the weighting function directly (Caliendo \& Kopeinig 2008; Stuart 2010). The present estimator does not suffer from this shortcoming as it is just a rewriting of matching estimators and the propensity score does not enter the weighting directly.

${ }^{6}$ I use the program "psmatch2" (Leuven \& Sianesi 2003) in Stata 11 to compute $\omega(j)$.

${ }^{7}$ See Smith \& Todd (2005), Caliendo \& Kopeinig (2008) and Stuart (2010) for excellent descriptions of the various matching procedures.
} 
control groups, there is no one best matching procedure for all situations (Caliendo \& Kopeinig 2008). Yet, Heckman et al. (1997) and Smith \& Todd (2005) argue for the use of kernel matching, which is the method primarily used in this study. To test the sensitivity of the results with respect to different matching procedures, I also apply 5to-1 nearest neighbor caliper matching as a robustness check. For kernel matching the weights take on the form

$$
\omega(i, j)=\frac{K\left[\frac{P_{j}-P_{i}}{b_{n}}\right]}{\sum_{j} K\left[\frac{P_{j}-P_{i}}{b_{n}}\right]},
$$

where $P$ is the linear index of the propensity score, $K[\cdot]$ is a specific kernel function and $b_{n}$ is a bandwidth parameter. There is a general agreement that the choice of the kernel is less crucial than the choice of the bandwidth. I use the Epanechnikov kernel due to its slight superiority in terms of efficiency. The chosen bandwidth is 0.06 as applied by Heckman et al. (1997). Although Smith \& Todd (2005) find their results to be robust against different bandwidth choices, in the section on robustness checks I apply a different bandwidth. The third step is the regression step, where I compute the ATT according to equation (3). I include all conditioning variables $S$ from the propensity score equation in $\mathbf{X}$. While the calculation of the weights is performed within cells, the ATT is computed for the pooled sample.

The applied regression-adjusted difference-in-difference matching estimator improves conventional matching estimators in several ways. First, the DiD matching estimator eliminates the time-invariant outcome difference between individuals in the treatment and control group. The pure cross-sectional matching estimator assumes that all relevant variables that determine job loss and influence the level of health behaviors are included in the data set - and incorporated into the model. This is a much stronger assumption. Second, the regression-adjusted matching estimator remains consistent if either the propensity score equation or the regression equation is correctly specified. Therefore, the researcher has two opportunities to deal correctly with the selection bias and, hence, the model can be regarded as doubly robust (Bang \& Robins 2005). The inclusion of all variables from the propensity score estimation reduces the effect of prevailing covariate imbalances after matching and, thus, decreases the small sample and asymptotic bias of the matching estimator (Abadie \& Imbens 2006). Furthermore, including relevant variables in the regression step decreases unexplained variance in the outcome and, hence, the standard errors of the treatment effect estimates. This is similar to including control variables in randomized experiments. Third, I combine propensity 
score matching with exact matching on survey year and baseline smoking status, which I regard as crucial variables for the purpose of this study. Smoking initiation and smoking cessation are different decisions and the distinction between these two decisions is useful (DeCicca et al. 2008). Therefore, I display smoking results separately for smokers and nonsmokers and match exactly on the smoking status to compare only like and like. Performing inexact matching on survey year would imply comparing individuals from different time periods. Fourth, the matching and analysis steps are clearly separated. Therefore, the quality of the matching procedure is evaluated prior to the computation of the ATT. In this sense matching per se is not a data analysis tool but rather a preprocessing step (Ho et al. 2006).

To highlight some benefits of the applied matching procedure, the presentation of the results in table 3 starts with a simple specification without pre-treatment health behavior information and without exact matching. The other specifications gradually incorporate the more sophisticated procedures.

There is a debate in the literature as to how to estimate the variance of propensity score-based matching estimators (see Caliendo \& Kopeinig 2008; Stuart 2010). The crux is that the variance estimation should take into account uncertainty in the propensity score estimation. Although there is evidence that standard errors are overestimated if the estimated propensity score is used instead of the true propensity score (see Stuart 2010). Hence, if the uncertainty in the propensity score model is not considered, erring might be on the conservative side. Usually bootstrapping constitutes a popular way of estimating standard errors when they are difficult to compute analytically or when the theoretical distribution of the relevant statistic is unknown. However, there is no formal justification for the application of the bootstrap in the case of matching and Abadie \& Imbens (2008) show that bootstrapping fails in the case of nearest neighbor matching. Therefore, this study does not rely primarily on bootstrapped standard errors. ${ }^{8}$ Instead I use robust standard errors from the weighted regressions. Robustness tests in section 7 show that the applied standard errors are slightly more conservative than comparable bootstrapped standard errors and standard errors computed according to the formula suggested by Lechner (1999). ${ }^{9}$

\footnotetext{
${ }^{8}$ Although some argue that bootstrapping might be valid in the case of kernel matching, which does not rely on a fixed number of matches and is thus smoother (Todd 2008).

${ }^{9}$ Lechner (1999) approximates the variance of the ATT by
}

$$
\sigma_{A T T}^{2}=\frac{1}{N_{1}} \cdot \operatorname{Var}\left(Y_{1} \mid D=1, M=1\right)+\frac{\sum_{j \in I_{0}} \omega_{j}^{2}}{N_{1}^{2}} \cdot \operatorname{Var}\left(Y_{0} \mid D=0, M=1\right),
$$




\section{Data and Variables}

This study uses data from the 2002-2010 waves of the German Socio-Economic Panel Study (SOEP), which is one of the largest and longest running survey panels in the world. Annually it conducts interviews with more than 20,000 individuals in over 10,000 households in Germany (Wagner et al. 2007). The SOEP provides a wide range of information at the individual and the household level, e.g. about working and living conditions. In even number years, starting in 2002, the SOEP includes a detailed health module, which I use to construct the outcome measures.

\subsection{Outcome Variables}

This study analyzes two different types of health behavior, smoking and body weight. I use information about smoking behavior and body weight from the 2002, 2004, 2006, 2008 and 2010 waves. The SOEP does not elicit this information in the odd numbered years. I look at two different smoking measures: the daily number of cigarettes smoked and a dummy variable indicating whether or not an individual currently smokes. For the current smoking status, I distinguish between smoking initiation (the decision of nonsmokers to start smoking), smoking continuation (the decision of smokers to remain smokers) and smoking participation (the smoking decisions of smokers and nonsmokers combined) following DeCicca et al. (2008). I exclude observations of those who solely smoke pipes or cigars.

Body weight is reported in kilograms. Since I analyze effects on changes in body weight, these effects directly translate into changes in the body mass index, BMI (assuming a constant height). However, effects are easier to interpret in terms of changes in kilograms than in terms of changes in BMI, which is defined as the individual's body weight divided by the square of the individual's height and measured in $\mathrm{kg} / \mathrm{m}^{2}$. The study does not consider overweight status $(\mathrm{BMI}>25)$ or obesity $(\mathrm{BMI}>30)$ directly because few individuals in the sample change between these (arbitrary) weight categories. A gain in body weight is not necessarily bad for health, especially for underweight people. Yet, more than half of the treated individuals are overweight and more than $15 \%$ of them are obese. Section 8 looks at whether there are differences in job loss induced body weight changes between overweight and normal weight individuals.

where $N_{1}$ denotes the number of matched $(M=1)$ treated $(D=1), I_{0}$ the control group and $\omega(j)$ the total weight of control $j$, i.e. $\omega(j)=\sum_{i \in I_{1}} \omega(i, j)$. This variance estimation takes into account that control observations might be used multiple times as matches and was found to produce similar results to the bootstrap approach (Lechner 2002). 


\subsection{Treatment and Control Group}

Treatment and control group consist of individuals between 18 and 62, who were neither self-employed nor civil servants and who were working either full or part-time during the pre-treatment period (denoted by $t-1$ ). I only include individuals with non-missing smoking and body weight information before and after treatment. This drops the sample size by about $2 \%$. The treatment group comprises individuals who lost their job due to plant closure or dismissal between two survey rounds with information about the individuals' health behaviors, i.e. between $t-1$ and $t+1$. For the control group, I only select those individuals without job change between $t-1$ and $t+1$. Note that the SOEP includes the information on health behaviors only every two years. Hence, between $t-1$ and $t+1$ a survey round without questions on health behaviors takes place (at time $t$ ). Since the question about job loss in the SOEP incorporates all job losses occurring during the survey year and the previous year, the information about job loss is derived from either the interview in $t$ or $t+1$. All other data originate from $t-1$, the last wave with information about the individuals' health behaviors before the treatment. On average, this last interview took place eleven months before the job loss. The time between job loss and the following interview is, on average, thirteen months.

The study only looks at involuntary job loss and, therefore, does not include individuals who voluntarily terminated their employment (including, for example, resignation or mutual agreement), because selection issues might arise. Further, it is not clear from a theoretical point of view, why this should lead to a change in health behaviors. It might be argued that individuals are dismissed because of a change in smoking behavior or body weight. Dismissals due to a high level of smoking or weight should not distort the results since the levels are taken into account in the matching procedure. To show that there is no reverse causality, I also perform analyses in which the treatment group only consists of individuals who lost their jobs due to plant closure, for which exogeneity is stricter. In the whole observation period there are 1,768 incidences of involuntary job loss. Since only 520 occurred due to plant closure, I do not solely rely on these cases. The potential control group consists of more than 22,500 observations.

\subsection{Conditioning Variables}

The identification strategy builds on the assumption that the model includes all variables that simultaneously influence the probability of job loss and changes in health behaviors. Therefore, the choice of the conditioning variables $S$ is crucial. I reviewed variables used 
Table 1: Overview of the conditioning variables

\begin{tabular}{|c|c|}
\hline \multicolumn{2}{|l|}{ Demographic } \\
\hline Female & $0=$ male, $1=$ female \\
\hline Age & in years; third order polynomial \\
\hline Migrant & $1=$ individual or parents moved to Germany, 0 else \\
\hline Non-German & $0=$ German, $1=$ foreign citizenship \\
\hline Home owner & $0=$ tenant, $1=$ home owner \\
\hline Spouse & $1=$ married or unmarried spouse in the household, 0 else \\
\hline Children & $1=$ children under 18 in household, 0 else \\
\hline Survey year & 4 categories $(2002,2004,2006,2008)$ \\
\hline $\begin{array}{l}\text { Labor market } \\
\text { Labor earnings } \\
\text { Never unemployed } \\
\text { Years unemployed } \\
\text { Tenure } \\
\text { Blue collar } \\
\text { Perceived job security } \\
\text { Company size }^{+} \\
\text {Industry sector }\end{array}$ & $\begin{array}{l}\text { logarithm of annual earnings in Euro } \\
0=\text { ever unemployed, } 1=\text { never unemployed } \\
\text { years with months in decimal form } \\
\text { in years } \\
0=\text { white collar, } 1=\text { blue collar worker } \\
3 \text { categories (big worries, some worries, no worries) } \\
3 \text { categories ( }<20,20-200,>200 \text { employees) } \\
10 \text { categories }\end{array}$ \\
\hline $\begin{array}{l}\text { Educational } \\
\text { University } \\
\text { Vocational training } \\
\text { Secondary schooling } \\
\end{array}$ & $\begin{array}{l}0=\text { no university degree, } 1=\text { university degree } \\
0=\text { no vocational training, } 1=\text { vocational training } \\
4 \text { categories (no degree/basic school, intermediate/other school } \\
\text { academic school track (Abitur), technical school) }\end{array}$ \\
\hline $\begin{array}{l}\text { Regional } \\
\text { Residential district } \\
\text { Federal state }\end{array}$ & $\begin{array}{l}4 \text { cat. }(<2000,2000-20000,20000-100000,>100000 \text { inhabitants }) \\
12 \text { categories }{ }^{11}\end{array}$ \\
\hline $\begin{array}{l}\text { Health } \\
\text { Self-rated health } \\
\text { Private health insurance } \\
\text { Mental health }^{+} \\
\text {Physical health }^{+} \\
\text {Baseline smoker } \\
\text { Number of cigarettes } \\
\text { Ever-smoker } \\
\text { Heavy smoker } \\
\text { Partner smokes } \\
\text { Overweight } \\
\text { Body weight } \\
\text { BMI } \\
\text { Height } \\
\text { Drinking behavior }\end{array}$ & $\begin{array}{l}3 \text { categories (very good/good, satisfactory, poor } / \text { bad) } \\
0=\text { public, } 1=\text { private health insurance } \\
\text { based on SF12 questionnaire (see Andersen et al. } 2007 \text { ), cardinal } \\
\text { based on SF12 questionnaire, cardinal measure } \\
0=\text { baseline nonsmoker, } 1=\text { smoker before treatment } \\
\text { daily number of cigarettes } \\
0=\text { never smoked; } 1=\text { ex-smoker(asked only in } 2002 \text { survey) } \\
0=<20 \text { cigarettes } / \text { day, } 1=\geq 20 \text { cigarettes a day } \\
0=\text { partner is nonsmoker, } 1=\text { partner smokes } \\
0=\mathrm{BMI} \leq 25,1=\mathrm{BMI}>25 \\
\text { in kg } \\
\text { body mass index; in kg } / \mathrm{m}^{2} \\
\text { in centimeters } \\
4 \text { cat. (regular, moderate, rare drinker, abstainer) }{ }^{12}\end{array}$ \\
\hline
\end{tabular}

Variables with an additional category for missing values marked with ${ }^{+}$.

${ }^{11}$ I group Rhineland-Palatinate with Saarland, Bremen with Lower Saxony, Hamburg with SchleswigHolstein and Mecklenburg-West Pomerania with Brandenburg due to small numbers of observations.

${ }^{12}$ Coding according to Ziebarth \& Grabka (2009). Data on drinking behavior only available since 2006. 11 
in other studies analyzing effects of job $\operatorname{loss}^{10}$ and include as many of these variables as possible. Since I rely on rich survey data, I can not only include more conditioning variables than any one of these other studies but I can also use almost all conditioning variables from these studies. It is even possible to include perceived job security, which was found to be a good predictor of subsequent job loss also when controlling for other characteristics (Stephens 2004). With respect to the outcome variables, the data allow to condition not only on smoking behavior and body weight prior to job loss but also on the smoking history, i.e. whether individuals ever smoked 100 cigarettes in their life.

Matching variables can be roughly divided into demographic, labor market-related, educational, regional and health-related (see table 1). In order to not lose treatment observations with missing values on some conditioning variables, I set missing values to 0 and include binary variables indicating a missing value. The affected variables are marked with "+" in table 1. Hence, I treat missing values as just another category of these variables. Matching is therefore not only on the observed values but also on the missing data pattern (Stuart 2010). The ATT estimates are very similar when observations with missing values are excluded, the standard errors, however, slightly increase (results are not shown, but are available upon request). In total, the study conditions on 75 non-collinear variables.

\section{Matching Quality}

The quality of matching can be assessed by comparing the means of the conditioning variables for treated and untreated after matching. If the means of treated and matched controls deviate very much, matching on the linear propensity score did not work well and rather different observations are compared. To determine whether a mean difference is large, I look at the standardized bias. The standardized bias displays for each conditioning variable $S$ the difference between the means of treated $\left(s_{1}\right)$ and matched controls $\left(s_{0}\right)$ as a percentage of the square root of the average of the variances $\left(\sigma_{s}^{2}\right)$ in the two groups (Rosenbaum \& Rubin 1985b):

$$
S B_{s}=100 \cdot \frac{\overline{s_{1}}-\overline{s_{0}}}{\sqrt{\frac{1}{2}\left(\sigma_{s 1}^{2}+\sigma_{s 0}^{2}\right)}}
$$

When the standardized bias exceeds $5 \%$, the mean difference is regarded to be large

\footnotetext{
${ }^{10}$ These are Browning et al. (2006), Böckerman \& Ilmakunnas (2009), Eliason \& Storrie (2009), Falba et al. (2005), Salm (2009), Schmitz (2011) and Sullivan \& Wachter (2009).
} 
Table 2: Means of treated, controls and matched controls

\begin{tabular}{|c|c|c|c|c|c|}
\hline \multirow[t]{2}{*}{ Variable } & \multirow[t]{2}{*}{ Treated } & \multicolumn{2}{|c|}{ Controls } & \multicolumn{2}{|c|}{ Standard. Bias (\%) } \\
\hline & & unmatched & matched & unmatched & matched \\
\hline \multicolumn{6}{|l|}{ Demographic } \\
\hline Female $^{+}$ & 41.11 & 47.11 & 42.26 & -12.10 & -2.33 \\
\hline Age & 40.88 & 42.71 & 41.12 & -17.98 & -2.27 \\
\hline Migrant $^{+}$ & 19.73 & 15.36 & 19.72 & 11.51 & 0.01 \\
\hline Non-German $^{+}$ & 15.44 & 11.59 & 15.55 & 11.26 & -0.30 \\
\hline Home owner ${ }^{+}$ & 40.54 & 54.27 & 40.66 & -27.75 & -0.25 \\
\hline Spouse $^{+}$ & 73.58 & 78.76 & 74.34 & -12.17 & -1.71 \\
\hline Children $^{+}$ & 40.08 & 41.12 & 39.18 & -2.12 & 1.84 \\
\hline \multicolumn{6}{|l|}{ Labor market } \\
\hline Labor earnings & 10.37 & 10.76 & 10.38 & -40.54 & -0.96 \\
\hline Never unemployed ${ }^{+}$ & 44.25 & 68.39 & 45.43 & -50.17 & -2.36 \\
\hline Years unemployed & 1.08 & 0.44 & 1.08 & 40.38 & -0.32 \\
\hline Tenure & 6.58 & 11.67 & 6.81 & -58.07 & -3.04 \\
\hline Blue collar ${ }^{+}$ & 49.06 & 32.90 & 48.53 & 33.30 & 1.06 \\
\hline Big job worries ${ }^{+}$ & 34.25 & 15.32 & 35.00 & 44.93 & -1.58 \\
\hline No job worries $^{+}$ & 20.41 & 38.85 & 20.24 & -41.23 & 0.43 \\
\hline $\mathrm{No} \mathrm{info}^{+}$ & 1.66 & 1.44 & 2.16 & 1.78 & -3.67 \\
\hline Small company ${ }^{+}$ & 39.51 & 20.79 & 39.14 & 41.66 & 0.74 \\
\hline Medium company $^{+}$ & 32.76 & 29.75 & 32.94 & 6.51 & -0.37 \\
\hline Large company $^{+}$ & 25.56 & 46.95 & 25.63 & -45.63 & -0.16 \\
\hline No company info ${ }^{+}$ & 2.17 & 2.52 & 2.29 & -2.29 & -0.79 \\
\hline \multicolumn{6}{|l|}{ Education } \\
\hline University $^{+}$ & 5.95 & 7.63 & 6.23 & -6.70 & -1.18 \\
\hline Vocational training $^{+}$ & 55.86 & 50.38 & 55.70 & 10.99 & 0.32 \\
\hline Basic school $^{+}$ & 32.65 & 28.28 & 32.53 & 9.50 & 0.24 \\
\hline Intermediate school $^{+}$ & 47.51 & 43.85 & 47.81 & 7.35 & -0.59 \\
\hline Technical college ${ }^{+}$ & 3.95 & 6.52 & 3.91 & -11.57 & 0.19 \\
\hline Highest secondary $^{+}$ & 13.38 & 19.66 & 13.24 & -16.96 & 0.42 \\
\hline No schooling info $^{+}$ & 2.52 & 1.70 & 2.51 & 5.71 & 0.01 \\
\hline \multicolumn{6}{|l|}{ Regional } \\
\hline Village $^{+}$ & 11.32 & 8.74 & 11.50 & 8.58 & -0.55 \\
\hline Small town ${ }^{+}$ & 34.25 & 35.47 & 33.96 & -2.56 & 0.61 \\
\hline Small city $^{+}$ & 26.59 & 27.16 & 26.70 & -1.30 & -0.25 \\
\hline Big city $^{+}$ & 27.84 & 28.62 & 27.85 & -1.73 & -0.00 \\
\hline
\end{tabular}


Table 2: Means of treated, controls and matched controls - Continued

\begin{tabular}{|c|c|c|c|c|c|}
\hline \multirow[t]{2}{*}{ Variable } & \multirow[t]{2}{*}{ Treated } & \multicolumn{2}{|c|}{$\overline{\text { Controls }}$} & \multicolumn{2}{|c|}{ Standard. Bias (\%) } \\
\hline & & unmatched & matched & unmatched & matched \\
\hline \multicolumn{6}{|l|}{ Health } \\
\hline Bad health $^{+}$ & 11.66 & 9.60 & 11.91 & 6.70 & -0.77 \\
\hline Good health $^{+}$ & 53.97 & 58.84 & 53.12 & -9.82 & 1.70 \\
\hline Private health insurance ${ }^{+}$ & 3.26 & 6.71 & 3.39 & -15.92 & -0.73 \\
\hline No insurance info $^{+}$ & 0.23 & 0.20 & 0.31 & 0.71 & -1.49 \\
\hline Mental health & 48.14 & 49.28 & 47.84 & -9.80 & 2.46 \\
\hline Physical health & 50.74 & 51.38 & 50.44 & -5.96 & 2.67 \\
\hline No health info ${ }^{+}$ & 2.17 & 1.96 & 2.50 & 1.47 & -2.17 \\
\hline Baseline smoker $^{+}$ & 42.71 & 33.60 & 42.71 & 18.84 & 0.00 \\
\hline Number of cigarettes & 7.31 & 5.49 & 7.34 & 18.42 & -0.28 \\
\hline Ever-smoker $^{+}$ & 63.64 & 57.34 & 63.58 & 12.91 & 0.12 \\
\hline No Ever-smoker info ${ }^{+}$ & 5.15 & 5.77 & 4.98 & -2.77 & 0.77 \\
\hline Heavy smoker ${ }^{+}$ & 19.73 & 14.73 & 19.61 & 13.26 & 0.30 \\
\hline Partner smokes ${ }^{+}$ & 26.59 & 23.12 & 26.94 & 8.03 & -0.79 \\
\hline No partner-smoke info ${ }^{+}$ & 29.79 & 25.45 & 28.94 & 9.72 & 1.87 \\
\hline Overweight $^{+}$ & 53.34 & 51.10 & 53.49 & 4.49 & -0.30 \\
\hline Body weight & 77.79 & 77.00 & 77.62 & 4.98 & 1.07 \\
\hline BMI & 25.82 & 25.67 & 25.82 & 3.34 & -0.02 \\
\hline Height & 173.22 & 172.82 & 173.04 & 4.41 & 1.94 \\
\hline Abstainer $^{+}$ & 4.52 & 3.71 & 4.44 & 4.07 & 0.38 \\
\hline Rare drinker $^{+}$ & 10.92 & 13.01 & 11.14 & -6.43 & -0.69 \\
\hline Moderate drinker ${ }^{+}$ & 16.52 & 20.67 & 16.54 & -10.66 & -0.04 \\
\hline Regular drinker ${ }^{+}$ & 6.86 & 8.35 & 6.82 & -5.61 & 0.17 \\
\hline No alcohol info ${ }^{+}$ & 61.18 & 54.27 & 61.07 & 14.02 & 0.23 \\
\hline
\end{tabular}

Note: Summary statistics for treated, all controls and matched controls. The first three columns present the means of selected variables before treatment for treated, controls and matched controls, respectively. The last two columns display the standardized bias in $\%$ before and after matching. + indicates that the mean represents a percentage share.

(Caliendo \& Kopeinig 2008), and balancing did not work very well. Table 2 presents descriptive statistics for the pooled sample. Values for the matched controls are derived from the main matching specification, i.e. kernel matching (with an Epanechnikov kernel and a bandwidth of 0.06 ) on the covariates described in table 1 within cells defined by survey year and current smoking status. ${ }^{13}$

\footnotetext{
${ }^{13}$ Matching is also on the square and cubic of age as well as on sets of binary variables for federal state, survey year and industry (see section 4). Table 2 excludes these variables due to space limitations. Also for these variables the standardized bias falls below the critical value of $5 \%$ after matching. The calculation of the median standardized bias in tables 3 and 4 considers these variables.
} 
After imposing the common support conditions, the sample comprises 1,749 treated observations ( 515 with plant closure). This reduces the sample size by about $1 \%$. The standardized bias is much smaller after matching and never exceeds the critical value of $5 \%$. The median standardized bias over all 75 conditioning variables is 10.06 before matching and 0.73 after matching; the mean standardized bias amounts to 0.88 . For other matching procedures, tables 3 and 4 present the median standardized bias and the share of treated observations off the common support together with the ATT estimates. In general, the median standardized bias is rather low compared to other studies (e.g. Lechner 2002; Blundell et al. 2005; Kuhn et al. 2009). Based on this criterion the matching procedure succeeds.

Before matching, those who lost their jobs differ. For instance, they are more likely to be blue collar workers, have less work experience, work more often in small companies, have more previous unemployment, are more concerned about the security of their jobs, have lower levels of secondary education, have lower levels of income and, more likely to have a migration background. With respect to the health behaviours analyzed, the treated are more likely to smoke (43\% vs. $34 \%$ ), have a higher BMI on average and are more likely to be overweight (53\% vs. $51 \%$ ) before job loss. Matching strongly reduces these disparities in health behaviors as well as in other conditioning variables. Therefore, matching seems to function properly. Small remaining differences between treated and matched controls are mitigated by the regression-adjustment.

\section{Results}

Table 3 presents the estimates of the effect of job loss on body weight and smoking (ATT) for several specifications (i) for all individuals and separately for (ii) baseline smokers and (iii) baseline nonsmokers. The table starts with the simplest specification in the first column. The other specifications gradually incorporate more sophisticated procedures. Specification (4) is the preferred specification. For each specification, table 3 also presents the share of treated observations off the common support, i.e. treated individuals without adequate match, and the median of the standardized bias as defined in section 5 .

Specification (1) does not use any information about the pre-treatment health behaviors in the estimation of the linear propensity score, the outcome variable or for regression adjustment. ${ }^{14}$ Hence, I do not present results separately for baseline smok-

\footnotetext{
${ }^{14}$ Variables concerning smoking status, smoking intensity and smoking history as well as variables about body weight and BMI are excluded in this specification.
} 
ers and nonsmokers. This specification most closely resembles a pure cross-sectional matching estimator. Matching is not exact on survey year and baseline smoking status in this specification. In this specification, job loss increases smoking participation by 5 percentage points, the daily number of cigarettes smoked by 0.7 cigarettes and the body weight by $0.6 \mathrm{~kg}$ - although the effect on body weight is not significant at common significance levels.

Specification (2) is the difference-in-difference matching estimator where the outcome is the change in health behavior and where the propensity score estimation takes into account $Y^{b}$, the pre-treatment health behaviors. For the pooled sample, job loss increases the probability of smoking by 2.4 percentage points and increases body weight by around $0.3 \mathrm{~kg}$. This is in addition to the usual weight gain between two observation periods, which is $1.00 \mathrm{~kg}$ for the matched controls. Therefore, the total body weight increase amounts to $1.32 \mathrm{~kg}$ for the treated. The effect on the current smoking status is principally driven by baseline nonsmokers starting to smoke. There is no significant increase in the probability of baseline smokers remaining smokers. Smokers also do not smoke significantly more cigarettes, on average, after their job loss. Compared to specification (1), the effect of job loss on health behaviors is considerably smaller. If there was no selection on unobservable characteristics with time-invariant effects, the estimates of the ATT should be very similar. The large differences might be taken as an indication that the cross-sectional matching estimator of specification (1) is biased upwardly.

While for specification (2) matching is on the linear index of the propensity score of the pooled sample, specification (3) additionally performs exact matching on survey year and smoking status. The median standardized bias is similar, while the share of treated observations outside the common support increases slightly. The results resemble the results of the previous specification.

In specification (4) there is additional regression adjustment for all conditioning variables used in the estimation of the propensity score. As expected, regression adjustment slightly decreases the standard errors compared to specification (3). Some estimated effects decrease somewhat in magnitude. The change in body weight amounts to $1.0 \mathrm{~kg}$ for the matched controls. Therefore, the job loss-related rise in body weight denotes an increase in body weight change of less than 30 percent. Among the matched controls less than 5.3 percent of the baseline nonsmokers start smoking. The estimated 3.0 percentage point increase implies an increase in the probability of starting smoking of more than 50 percent.

This effect is somewhat smaller than the effect in Falba et al. (2005), who estimate that 
Table 3: Estimates of the ATT

\begin{tabular}{lcccc}
\hline \hline & $(1)$ & $(2)$ & $(3)$ & $(4)$ \\
\hline All individuals & & & & \\
Smoking participation & $0.051^{* * *}$ & $0.024^{* * *}$ & $0.025^{* * *}$ & $0.025^{* * *}$ \\
& $(0.013)$ & $(0.008)$ & $(0.008)$ & $(0.008)$ \\
Number of cigarettes & $0.694^{* * *}$ & 0.167 & 0.240 & 0.193 \\
& $(0.261)$ & $(0.175)$ & $(0.201)$ & $(0.162)$ \\
Body weight & 0.609 & $0.322^{* *}$ & $0.281^{*}$ & $0.274^{*}$ \\
& $(0.436)$ & $(0.154)$ & $(0.158)$ & $(0.154)$ \\
& & & & \\
Baseline nonsmokers & & & & \\
Smoking initiation & & $0.030^{* * *}$ & $0.030^{* * *}$ & $0.030^{* * *}$ \\
& & $(0.009)$ & $(0.009)$ & $(0.009)$ \\
Baseline smokers & & & & \\
Smoking continuation & & 0.019 & 0.020 & 0.017 \\
& & $(0.013)$ & $(0.014)$ & $(0.013)$ \\
Number of cigarettes & & 0.034 & 0.160 & 0.002 \\
& & $(0.363)$ & $(0.425)$ & $(0.342)$ \\
\hline Off common support $(\%)$ & 0.00 & 0.06 & 1.07 & 1.07 \\
Median std. bias & 0.84 & 0.81 & 0.59 & 0.59 \\
\hline Outcome & $Y^{a}$ & $\Delta Y_{t}$ & $\Delta Y_{t}$ & $\Delta Y_{t}$ \\
$Y^{b}$ in PS & no & yes & yes & yes \\
in cells & no & no & yes & yes \\
Regression adjustment & no & no & no & yes \\
Matching & kern & kern & kern & kern \\
S-variables & all & all & all & all \\
Treatment & T1 & T1 & T1 & T1 \\
\hline \hline
\end{tabular}

Note: The table presents the effect of job loss on smoking and body weight. Each cell displays the ATT from a separate regression and its robust standard error. Row names indicate the outcome. $Y^{b}$ refers to the health behavior before treatment, $Y^{a}$ to the health behavior after treatment. $\Delta Y_{t}=Y^{a}-Y^{b}$. Treatment group T1 includes all individuals who lost their jobs due to plant closure or dismissal. The matching method "kern" refers to kernel matching. The row "Median std. bias" displays the median of the standardized bias over all matching variables. "Off common support" indicates the share of treated individuals (from a base of $N=1,768$ ) who are not considered in the estimation due to inappropriate matches. ${ }^{*} p<0.1 ; * * p<0.05 ;{ }^{* * *} p<0.01$. 
job loss more than doubles the probability of smoking initiation. However, Falba et al. (2005) not only apply a different estimation strategy and analyze U.S. individuals aged over 50 , but they also focus solely on ex-smokers and, therefore, on smoking relapse. In section 8 , I perform separate analyses for ex-smokers. I find that for ex-smokers job loss increases the probability of (re)starting smoking by about 50 percent ( 5.7 percentage points), which is, again, smaller than the effect in Falba et al. (2005). The average increases in body weight differ from findings of Deb et al. (2011), who only observe significant increases for one latent group in their finite mixture models. This group consists of individuals who already engage in unhealthy behaviors before job loss. For this group, Deb et al. (2011) estimate a job loss-related increase in BMI by more than one unit. This considerably exceeds the (average) effect I estimate. The $0.274 \mathrm{~kg}$ increase in body weight translates into an increase of less than one tenth of a BMI unit. Section 8 performs separate analyses for different at-risk groups and shows that for overweight individuals the effect is larger but still considerably below one BMI unit.

To gauge whether the statistically significant effects in specification (4) are meaningful, the findings of this study are compared with other effects on smoking and body weight reported in the literature. Ruhm (2005) estimates that a one point drop in the employment rate in the U.S. reduces the estimated smoking participation rate by 0.13 percentage points on the aggregate level. In contrast, I find individual job loss to increase smoking participation by 2.5 percentage points. This effect is almost twenty times as large. If healthy living really improves during economic downturns and smoking participation of individuals experiencing job loss increases, there must be some groups (e.g. employed individuals with reduced working hours) for which smoking rates decrease even more than the average estimated by Ruhm (2005). Exploiting large cigarette tax increases in the U.S., DeCicca \& McLeod (2008) find that a $\$ 1$ increase in the cigarette excise tax reduces smoking participation by 1.0-1.5 percentage points. For body weight, job loss resulted in an estimated increase of $0.274 \mathrm{~kg}$ in table 3, which equates to an increase in BMI of less than 0.1 units. This is considerably less than the reduction in BMI of 0.64 units resulting from a one point reduction in the employment rate (Ruhm 2005). In light of these other findings, the statistically significant increase in body weight seems to be of minor economic significance, while the increase in smoking participation seems to be rather high. 


\section{Robustness}

This section conducts various robustness checks and analyzes the plausibility of the identifying assumption. First, I apply a different bandwidth in the construction of the kernel weights. Second, I deal with a different selection of the conditioning variables. Third, I test the robustness of the findings with respect to a different matching procedure. Fourth, to check whether reverse causality might undermine the results, I only consider a specific subgroup of the treatment group. Further, I perform two placebo regressions to test the plausibility of the assumption of no selection on unobservables. Table 4 displays the results for the four robustness checks and the two placebo regressions. This section also discusses inference issues and arguments why the ATT estimates might be rather lower bound estimates.

For the first robustness check, I chose a bandwidth that is half the size of the previous bandwidth, i.e. $b_{n}=0.03$. Compared to the previous bandwidth, this bandwidth puts an even greater weight on close control observations. While this might increase consistency, it might also increase variance. This robustness test deviates from the three-step-procedure outlined above only in the second step, the computation of the weights in equation (3). Specification (5) in table 4 presents the associated results. Comparing with the main specification (4) of table 3 , the different bandwidth choice does not considerably change the results. The only notable difference is that effect on body weight becomes significant on the $5 \%$ level. Due to the smaller bandwidth of the Epanechnikov kernel, the number of treated individuals outside the common support increases marginally.

The choice of the conditioning variables, $S$, is crucial for the identification strategy. Therefore, the second robustness check tests the sensitivity of the results with respect to a different composition of conditioning variables. The specifications in the previous section use a set of conditioning variables that tries to incorporate all variables employed in related studies. The inclusion of many variables increases the chance of including all relevant variables. However, there are two shortcomings to this strategy (Caliendo \& Kopeinig 2008). First, including irrelevant variables does not bias the propensity score estimates but can increase their variance. This, in turn, will make the ATT estimates less precise. Second, this strategy might reduce the common support. The more variables are considered, the more difficult it is to find similar matches. In the second robustness test, I perform stepwise Probit regression in the pooled sample with forward selection in the propensity score step, where I only include variables that are 
Table 4: Robustness Checks

\begin{tabular}{lcccc|cc}
\hline \hline & $(5)$ & $(6)$ & $(7)$ & $(8)$ & $(9)$ & $(10)$ \\
\hline All individuals & & & & & & \\
Smoking participation & $0.025^{* * *}$ & $0.027^{* * *}$ & $0.030^{* * *}$ & 0.010 & -0.001 & $0.029^{*}$ \\
& $(0.008)$ & $(0.008)$ & $(0.008)$ & $(0.014)$ & $(0.010)$ & $(0.017)$ \\
Number of cigarettes & 0.157 & 0.169 & 0.247 & -0.153 & -0.217 & $0.580^{*}$ \\
& $(0.163)$ & $(0.162)$ & $(0.173)$ & $(0.254)$ & $(0.205)$ & $(0.348)$ \\
Body weight & $0.308^{* *}$ & $0.309^{* *}$ & $0.389^{* *}$ & $0.377^{*}$ & -0.110 & -0.255 \\
& $(0.152)$ & $(0.154)$ & $(0.159)$ & $(0.226)$ & $(0.188)$ & $(0.551)$ \\
& & & & & & \\
Baseline nonsmokers & & & & & & \\
Smoking initiation & $0.031^{* * *}$ & $0.032^{* * *}$ & $0.036^{* * *}$ & $0.030^{* *}$ & 0.013 & \\
& $(0.009)$ & $(0.009)$ & $(0.009)$ & $(0.014)$ & $(0.011)$ & \\
Baseline smokers & & & & & & \\
Smoking continuation & 0.016 & 0.019 & 0.023 & -0.026 & -0.021 & \\
& $(0.013)$ & $(0.013)$ & $(0.014)$ & $(0.025)$ & $(0.018)$ & \\
Number of cigarettes & -0.076 & -0.027 & 0.068 & -0.886 & -0.569 & \\
& $(0.347)$ & $(0.332)$ & $(0.365)$ & $(0.557)$ & $(0.437)$ & \\
\hline Off common support $(\%)$ & 1.53 & 0.96 & 0.85 & 0.96 & 0.53 & 0.53 \\
Median std. bias & 0.56 & 1.30 & 0.87 & 0.59 & 0.65 & 0.62 \\
\hline Outcome & $\Delta Y_{t}$ & $\Delta Y_{t}$ & $\Delta Y_{t}$ & $\Delta Y_{t}$ & $\Delta Y_{t-1}$ & $Y^{b}$ \\
$Y^{b}$ in PS & yes & yes & yes & yes & yes & no \\
in cells & yes & yes & yes & yes & yes & yes \\
Regression adjustment & yes & yes & yes & yes & yes & yes \\
Matching & kern2 & kern & NN & kern & kern & kern \\
S-variables & all & sig. & all & all & all & all \\
Treatment & T1 & T1 & T1 & T2 & T1 & T1 \\
\hline \hline & & & & & & \\
\hline
\end{tabular}

Note: The table presents the effect of job loss on smoking and body weight. Each cell displays the ATT from a separate regression and its robust standard error. Row names indicate the outcome. $Y^{b}$ refers to the health behavior before treatment. Treatment group T1 includes individuals who lost their jobs due to plant closure or dismissal (base $N=1,768$ ), T2 only considers job losses due to plant closure (base $N=520$ ). The matching method "kern" refers to kernel matching, "kern2" to kernel matching with a smaller bandwidth and "NN" to 5-to-1 nearest neighbor matching with caliper. "sig." means that not all conditioning variables are included but only those significant in stepwise propensity score estimations. ${ }^{*} p<0.1 ; * * p<0.05 ;{ }^{* * *} p<0.01$. 
significant on the $10 \%$ level. This set of conditioning variables comprises 27 variables, compared to 75 in the main specification. ${ }^{15}$ After the determination of this alternative set of conditioning variables, I proceed with the three-step procedure outlined above with the only differences being the application of a different set of conditioning variables both in propensity score estimation and regression-adjustment.

The results in specification (6) show that the significant effects do not change greatly when applying the different set of conditioning variables. The effects on smoking status and body weight increase slightly. The share of treated individuals off the common support decreases marginally as this specification considers fewer variables (from 1.07 $\%$ in specification (4) to $0.96 \%$ ). The median standardized bias takes a higher value (1.3) since I compute it over all conditioning variables of the main specification while propensity score and regression-adjustment consider only a subset of these variables.

For the third robustness test, this study makes use of a different matching procedure to compute the $\omega(i, j), 5$-to-1 nearest neighbor caliper matching. Morgan \& Harding (2006) consider nearest neighbor caliper matching with replacement superior to nearest neighbor matching without caliper and without replacement. 5-to-1 nearest neighbor matching assigns the five closest control group observations to any treatment group observation. The caliper prevents poor matches by ensuring that no control group individuals are matched who are too distant in terms of the linear propensity score. I apply a caliper of 0.25 standard deviations of the estimated linear propensity score, as recommended by Rosenbaum \& Rubin (1985a). With this form of matching, for each treated $i$, the weights $\omega(i, j)$ take on the values $1 / k_{i}$ for the $k_{i}$ nearest neighbors and 0 for all other non-treated. $k_{i}$ is 5 if the caliper is not binding, and between 0 and 4 if it binds. $k_{i}=0$ means that no good match exists and that the treatment observation is off the common support. Specification (7) presents the results for nearest neighbor caliper matching. Again, the effects are very similar but slightly larger, e.g. the effect on smoking initiation increases from 3.0 percentage points in specification (4) to 3.6 percentage points. As in the previous two robustness tests, the effect on body weight is significant at the $5 \%$ level. The median standardized bias is somewhat higher, while

\footnotetext{
${ }^{15}$ These variables include age $(-)$, age ${ }^{3}(+)$, female $(-)$, home owner $(-)$, labor earnings $(-)$, tenure $(-)$, company size 20-200 (-), company size > $200(-)$, no info on company size (-), big job worries $(+)$, no job worries $(-)$, previous years of unemployment $(+)$, no unemployment times $(-)$, construction industry $(+)$, health service industry $(-)$, other services (-), energy and water industry (-), BadenWürttemberg (-), Bavaria (-), Thuringia (+), Rhineland-Palatinate and Saarland (-), good health $(-)$, number of cigarettes $(+)$, partner smokes $(+)$, survey year $2004(-)$, survey year $2006(-)$ and survey year $2008(-)$. The signs in parentheses denote the association with the probability of job loss according to the propensity score equation.
} 
the common support improves.

If individuals were dismissed because of a change in smoking behavior or body weight, reverse causality would distort the previous results. Furthermore, other life-events might exist that influence both health behaviors and the dismissal probability. For instance, a divorce might increase an individual's level of smoking and, at the same time, reduce the individual's work motivation resulting in dismissal. For these two reasons, in specification (8) I only consider individuals who lost their job due to plant closure for the treatment group. This reduces the number of treated to less than one third of the original sample (520 observations). While plant closure is largely exogenous to the individual, frequently it does not come without warning. Those experiencing a plant closure might be a very selective group as these individuals did not leave the plant earlier (Kletzer 1998). Table 4 shows that the two main effects, the effect on body weight and the effect on the current smoking status for nonsmokers, are of similar magnitude to the base specification. For smokers, the effects on smoking status and the number of cigarettes remain insignificant but become negative. Therefore, the effect on smoking participation turns insignificant in the pooled sample.

To identify causal effects, all matching procedures assume that the conditioning variables, $S$, include all variables simultaneously influencing the probability of job loss and changes in health behaviors. There is no direct test for this assumption. However, I perform placebo regressions to add additional credibility to this assumption. The placebo regression pretends that the treatment takes place two years earlier. For example, if the actual job loss occurs between 2004 and 2006, the placebo treatment takes place between 2002 and 2004. Accordingly, for the first step I compute the propensity score based on conditioning variables obtained in the last year with health data before the placebo job loss (2002, in the example). Then, I proceed with the same three-step-procedure as before. The rationale behind this computation is as follows. If a job loss explains changes in health behaviors in the two years before job loss, there are probably some unobserved confounding variables making treated and matched controls different, which violates the unconfoundedness assumption. Table 4 shows that in specification (9) the placebo job loss does not influence changes in smoking behavior and body weight. All estimated effects are insignificant and close to zero. This specification adds plausibility to the assumption that there are no unobservables that influence both treatment and outcome in the preferred specification. The evolution of health behaviors of treated and matched controls is similar before the actual job loss.

An additional placebo regression is performed, where the outcome is the health be- 
havior (in levels) after the placebo job loss. This placebo regression resembles the crosssectional estimator of specification (1), which does not take into account any information about health behaviors before the (placebo) treatment in the propensity score equation, the definition of the outcome variable and for regression adjustment. Specification (10) indicates a violation of the unconfoundedness assumption when applying the crosssectional matching estimator. The placebo job loss affects the smoking behavior significantly, although it should not. This indicates that the matching difference-in-difference estimator clearly outperforms the cross-sectional estimator.

As outlined in section 3, the standard errors in tables 3 and 4 do not take into account that the propensity score is estimated. The displayed standard errors are robust standard errors derived from weighted regressions. These standard errors resemble bootstrapped standard errors (with 2,000 replications) and standard errors computed according to the formula suggested by Lechner (1999). They slightly exceed these standard errors implying more conservative inference. For instance, for the effect on smoking status' change in the pooled version of specification (2), the standard errors are 0.00755 in the bootstrap version and 0.00810 in the version according to Lechner (1999), while the robust standard errors I use are $0.00813 .{ }^{16}$ Applying different methods of standard error computation does not change the conclusions drawn.

Nevertheless, the ATT estimates might be downward-biased for several reasons. First, individuals who lost their job might underreport their true adverse health behaviors. This does not produce a bias in the DiD estimation if they underreport in the same way before job loss or if they change the degree of underreporting in the same way as the matched controls. However, if job loss makes them a stronger underreporter then the DiD estimation underestimates the true effect of job loss. It seems possible that the treated increase the degree of underreporting for not to fulfill prejudices against the unemployed. Second, those who experience a greater negative impact from their job loss (e.g. with respect to stress, finances or identity) might be more likely to drop out of the sample. ${ }^{17}$ These individuals might also be the most likely to cope with the job loss by increasing body weight and nicotine consumption. Third, often job losses do not come without warning. If the period before the actual job loss was already stressful and poor health

\footnotetext{
${ }^{16}$ Analogously, for changes in the number of cigarettes in the pooled sample these standard errors amount to 0.167 (bootstrap), 0.164 (Lechner) and 0.175 (this study), respectively. For body weight changes the respective standard errors take on the values 0.160 (bootstrap), 0.150 (Lechner) and 0.154 (this study).

${ }^{17}$ For instance, Dorsett (2010) finds unemployment to be related to panel attrition when comparing survey and register data.
} 
choices were how individuals coped with this increased stress, the pre-treatment outcome might incorporate the higher level of adverse health behaviors. There is some empirical evidence that the fear of unemployment harms mental health (Reichert \& Tauchmann 2011). However, the placebo regression in specification (9) does not indicate an impact of job loss on changes in health behavior before the job loss.

In general, the robustness checks support the conclusions of the previous section. Baseline nonsmokers are around 3 percentage points more likely to smoke due to job loss. On average, job loss increases the body weight by around 0.3 kilogram. However, there is no evidence that smokers intensify smoking. Neither the average number of cigarettes increases significantly nor the probability of them remaining smokers. The effects are very similar when only considering individuals experiencing job loss due to plant closure. The placebo regressions indicate the superiority of the matching DiD estimator compared to the cross-sectional estimator and add credibility to the unconfoundedness assumption.

\section{Heterogeneity Analysis}

While the two previous sections focus on average treatment effects, this section analyzes subgroup-specific treatment effects. Average effects might hide that some subgroups show no reaction to job loss while others show particularly strong reactions. Therefore, the analysis of treatment effect heterogeneity is crucial for acquiring a better understanding of the consequences of job loss on smoking behavior and body weight.

To facilitate a comparison of only like and like, in addition to exact matching on survey year and smoking status, I perform exact matching on the particular grouping variable. I apply the same three-step-procedure as before, but compute the weights in step 2 separately for each combination of year, smoking status and the grouping variable. This resembles specification (4) in table 3 with the exception that matching is exact on the grouping variable. Since I impose the same common support conditions as before, sample sizes might vary. Furthermore, these analyses drop observations with missing information on the grouping variable. I do not perform exact matching on all grouping variables simultaneously; the procedure outlined is repeated for each grouping variable. Grouping variables in table 5 include gender, age, partnership status, socioeconomic status, overweight status, health and unemployment status.

Table 5 shows the ATT for various subgroups and outcome variables. ${ }^{18}$ The first

\footnotetext{
${ }^{18}$ For reasons of brevity this table does not display the effects on the number of cigarettes for baseline smokers and nonsmokers combined but only for baseline smokers.
} 
Table 5: Treatment Effects by Subgroups

\begin{tabular}{lrccccc}
\hline \hline & & \multicolumn{2}{c}{ All individuals } & Nonsmokers & \multicolumn{2}{c}{ Smokers } \\
& & Smoking & & Smoking & Smoking & No. of \\
& $\mathrm{N}$ & Particip. & Body weight & Initiation & Contin. & Cigarettes \\
\hline Over 50 & 414 & $0.022^{*}$ & -0.041 & 0.006 & $0.063^{* *}$ & 0.055 \\
Under 50 & 1319 & $0.027^{* * *}$ & $0.353^{* *}$ & $0.041^{* * *}$ & 0.011 & 0.051 \\
Difference & & 0.006 & 0.393 & $0.035^{* *}$ & $-0.052^{*}$ & -0.003 \\
Male & 1025 & $0.026^{* *}$ & 0.016 & $0.044^{* * *}$ & 0.012 & -0.531 \\
Female & 716 & 0.017 & $0.863^{* * *}$ & $0.021^{* *}$ & -0.003 & 0.468 \\
Difference & & -0.009 & $0.847^{* * *}$ & -0.022 & -0.015 & 1.000 \\
Single & 448 & $0.047^{* * *}$ & -0.073 & $0.089^{* * *}$ & 0.008 & 0.772 \\
Partner & 1283 & $0.021^{* *}$ & $0.373^{* *}$ & $0.021^{* *}$ & 0.020 & -0.415 \\
Difference & & -0.027 & 0.446 & $-0.067^{* * *}$ & 0.012 & -1.187 \\
Lower educ. & 652 & $0.039^{* * *}$ & $0.477^{*}$ & $0.059^{* * *}$ & 0.021 & -0.847 \\
Higher educ. & 1039 & 0.016 & 0.195 & $0.022^{* *}$ & -0.000 & 0.185 \\
Difference & & -0.024 & -0.282 & $-0.037^{*}$ & -0.022 & 1.032 \\
Normal & 803 & $0.034^{* * *}$ & 0.054 & $0.043^{* * *}$ & 0.022 & -0.072 \\
Overweight & 924 & $0.019^{*}$ & $0.544^{* *}$ & $0.023^{* *}$ & 0.011 & 0.073 \\
Difference & & -0.016 & $0.490^{*}$ & -0.019 & -0.011 & 0.144 \\
Worse health & 803 & $0.050^{* * *}$ & 0.137 & $0.049^{* * *}$ & $0.051^{* * *}$ & 0.531 \\
Better health & 927 & 0.006 & $0.444^{* *}$ & $0.020^{*}$ & -0.015 & -0.614 \\
Difference & & $-0.044^{* * *}$ & 0.307 & -0.028 & $-0.067^{* *}$ & $-1.145^{*}$ \\
Job found & 1060 & $0.025^{* * *}$ & 0.208 & $0.027^{* *}$ & 0.019 & -0.293 \\
Unemployed & 689 & $0.024^{* *}$ & 0.390 & $0.038^{* * *}$ & 0.012 & 0.443 \\
Difference & & 0.001 & -0.182 & -0.011 & 0.007 & -0.736 \\
\hline \hline
\end{tabular}

Note: The table presents the effect of job loss on smoking and body weight for various subgroups defined by the row variables. Each cell stands for a separate ATT. Super columns indicate the smoking status before job loss, columns indicate the outcome. The first column displays the number of all treated observations in the region of common support for the various subgroups. Estimation resembles the procedure of specification (4) in table 3 with the difference that matching is additionally exact on the grouping variable. ${ }^{*} p<0.1 ;{ }^{* *} p<0.05 ;{ }^{* * *} p<0.01$. 
column displays the number of treated observations (smokers and nonsmokers together) in the region of common support for the subgroup defined by the row name. Two similar studies (Falba et al. 2005; Deb et al. 2011) analyze only individuals over the age of 50 . In order to make it easier to compare the results with these studies, I look at individuals who are aged 50 or older and contrast them with individuals younger than 50 . The first panel of table 5 shows that, due to job loss, young nonsmokers are significantly more likely to start smoking than their older counterparts. If this pattern is similar in the U.S., the probability of smoking initiation might be even higher in the general U.S. population than the results of Falba et al. (2005) indicate. Older baseline smokers are, however, significantly more likely to continue smoking due to job loss (6.3 vs. 1.1 percentage points).

It is often argued that work is more crucial for the identity of men and, hence, their reaction can be expected to be stronger. Roelfs et al. (2011) cite some studies that find stronger effects of job loss and unemployment on various outcomes for men. The second panel of table 5 shows that the effect of job loss on smoking initiation is stronger for men (4.4 vs. 2.1 percentage points). Although the difference is not statistically significant from zero. The only significant gender difference is with respect to the weight gain, which is considerably larger for women (0.86 vs $0.02 \mathrm{~kg}$ ). Overall, there appears to be no clear evidence for stronger effects of job loss on health behaviors of men.

The next panel compares individuals with and without cohabiting spouse. Spouses can give financial and emotional support, thus mitigating stress and financial hardship associated with job loss. Furthermore, spouses can work as control authority preventing individuals from increasing smoking and body weight after job loss. The data support these theoretical expectations for smoking behavior. Among baseline nonsmokers, single individuals are the group showing the highest increase in the probability of starting smoking (8.9 percentage points). As a result of the loss of employment they are significantly more likely to start smoking than individuals with a spouse in the household.

Individuals with less education might react particularly strongly to job loss as they might have less savings to compensate foregone earnings. They might also be less aware of the dangers of adverse health behaviors and have smaller social networks to provide emotional support (Cutler \& Lleras-Muney 2010). The results in the fourth panel support these considerations. Less educated individuals ${ }^{19}$ are more prone to initiate smoking due to job loss. This difference is substantial (3.7 percentage points) and significant. A

\footnotetext{
${ }^{19}$ Less educated means being in the lowest category of the CASMIN classification (inadequately completed, general elementary school or basic vocational qualification).
} 
similar picture emerges when the results are grouped according to other indicators of socioeconomic status, e.g. above vs. below median labor income, blue collar vs. white collar (results not shown). Socioeconomic gradients in the coping with job loss are found by other researchers as well (see Roelfs et al. (2011) for a discussion). For changes in body weight, though, no substantial differences are found between socioeconomic groups.

Deb et al. (2011) observe job loss-related increases in adverse health behaviors for individuals who have poor health behaviors prior to job loss. I can confirm this finding for body weight but not for smoking. Heavy smokers (smoking at least 20 cigarettes a day) and light smokers do not differ significantly in their reactions (results not shown). Yet, overweight individuals (BMI > 25) are more prone to increase their body weight as a consequence of job loss (see fifth panel of table 5). This might result in a vicious circle, since there is some evidence of recruitment discrimination due to body weight among specific subpopulations (Caliendo \& Lee 2011). However, also for overweight individuals the increase in body weight resulting from job loss amounts to clearly less than one kilogram. The next panel shows that individuals in the lowest self-rated health categories (satisfactory, poor or bad) are significantly more likely to start smoking and to continue smoking. This might further increase existing health differences, since smoking increases morbidity and mortality. There are no significant differences in the effects on body weight.

The last panel differentiates between whether the individual had found a job at the time of the following interview or was still unemployed. For this last grouping variable there is no need to recalculate the weights as the grouping rather reflects differences in the treatment. Although those in unemployment are slightly more likely to have started smoking (3.8 vs. 2.7 percentage points), there are no statistically significant differences between the two groups. This underlines that the job loss event is inherently stressful.

I analyzed differences in the effects of job loss for further subgroups. ${ }^{20}$ Although the unemployment level is higher in East Germany, job loss-related changes in health behaviors are similar in East and West Germany (results not shown). There is also no indication of a time trend in the effects of job loss: Individuals who lost their job in the first half of the observation period (i.e. before the 2006 survey) do not differ from individuals experiencing job loss in the second half. However, among baseline nonsmokers individuals with a smoking history (i.e. individuals who had ever smoked at least 100 cigarettes in their life) have a substantially and significantly higher chance of (re-)starting smoking; although also individuals who never smoked exhibit a positive

\footnotetext{
${ }^{20}$ These results are not displayed in table 5 for the sake of clarity but available on request.
} 
(but insignificant) probability of starting smoking due to the loss of employment.

Looking at the effects for all groups of table 5 together, it emerges that for each subgroup job loss increases the probability of starting smoking. This effect is significant for all groups, except for individuals over the age of 50. The increase in smoking initiation emerges as the most robust finding affecting almost all groups in society. While there is no evidence of an overall effect of job loss on the probability of continuing smoking, for some subgroups (over age 50, worse health) the probability of continuing smoking increases significantly. However, job loss does not cause a significant increase in smoking intensity among baseline smokers for a single subgroup. For most groups I estimate a job loss-related increase in body weight, which is, however, only significant for some subgroups.

\section{Conclusion}

This paper investigates the causal effect of job loss on smoking behavior and body weight. Using data from the German SOEP, this paper finds that job loss increases the probability of smoking initiation by 56 percent ( 3 percentage points). However, there is little evidence that baseline smokers intensify smoking or are less likely to stop smoking due to job loss. Job loss increases the body weight slightly (by about $0.3 \mathrm{~kg}$ ), but significantly. These findings emerge whether only those individuals who lost their jobs due to plant closure are considered, or all individuals experiencing job loss due either to plant closure or dismissal. The estimated causal effects of job loss can partly explain the positive association between unemployment and adverse health behaviors.

Compared to other effects on smoking and body weight (see e.g. Ruhm 2005; DeCicca \& McLeod 2008), the increase in smoking seems considerable, while the increase in body weight is rather small. In general, the effects on smoking and body weight fall below comparable findings for the U.S. (Falba et al. 2005; Deb et al. 2011), which might be attributable to the more generous unemployment assistance in Germany.

Analyses of the treatment effect heterogeneity indicate that almost all subgroups exert a significant increase in the probability of starting smoking due to job loss. This paper finds particularly high rates of smoking initiation among ex-smokers, young persons and individuals who are disadvantaged with respect to socioeconomic status, partnership status or health prior to job loss. While there is no overall effect of job loss on the probability of remaining a smoker, for some subgroups (over the age of 50, worse health) the probability of stopping smoking decreases significantly. However, job loss does not cause a significant increase in smoking intensity among baseline smokers for a single 
subgroup. With respect to body weight this paper finds larger effects for women and overweight individuals. The latter finding is in line with findings for the U.S. (Deb et al. 2011). Yet, also for overweight individuals the increase in body weight resulting from job loss amounts to less than one kilogram.

This study applies a regression-adjusted semiparametric difference-in-difference matching strategy (Heckman et al. 1997). This estimation strategy is robust against selection on observables and against selection on unobservables with time invariant effects. It is "double-robust" in the sense that it estimates treatment effects consistently if either the propensity score equation or the outcome equation is correctly specified. In order to interpret the estimated effects as causal effects, the estimation strategy assumes that no unobserved variables exist that simultaneously influence the probability of job loss and changes in the health behaviors. This paper provides an indirect test that the identifying assumption is not violated in the difference-in-difference estimator, but in the cross-sectional estimator that does not take into account health behaviors before the treatment. In general, the findings are robust over various matching specifications and different choices of the conditioning variables.

This study facilitates a better understanding of the implications of job loss, which is not only of particular importance in times of financial and economic crises. While previous studies find detrimental health effects of job loss (Eliason \& Storrie 2009; Sullivan \& Wachter 2009), this study emphasizes worsening health behaviors as potential mechanism for these findings. Other economic studies find that health behaviors improve at aggregated levels when unemployment is high (Ruhm \& Black 2002; Ruhm 2005). However, the present results show that simply transferring these findings to the individual level leads to an ecological fallacy. The improvement of health behaviors during economic downturns is not driven by newly unemployed (but possibly by employed individuals with reduced working hours). This micro-macro difference resembles other findings on the link between job loss and health: while mortality (Ruhm 2000) and infant health (Dehejia \& Lleras-Muney 2004) improve at aggregated levels when the unemployment rate is high, at the individual level job loss increases mortality (Eliason \& Storrie 2009; Sullivan \& Wachter 2009) and decreases infant health (Lindo 2011). The findings of this paper also emerge to be important from a public health perspective by highlighting that job loss is a crucial life event with a rather strong impact on smoking, one major cause of preventable deaths. Policies aimed at preventing smoking initiation might be more effective if they consider the vulnerability of specific groups, such as individuals who lost their employment. 


\section{References}

Abadie, A. \& Imbens, G. W. (2006). Large sample properties of matching estimators for average treatment effects. Econometrica, 74(1), 235-267.

Abadie, A. \& Imbens, G. W. (2008). On the failure of the bootstrap for matching estimators. Econometrica, 76(6), 1537-1557.

Adam, T. C. \& Epel, E. S. (2007). Stress, eating and the reward system. Physiology 8 Behavior, 91(4), 449-458.

Akerlof, G. \& Kranton, R. (2000). Economics and identity. Quarterly Journal of Economics, 115(3), 715-753.

Andersen, H., Mühlbacher, A., Nübling, M., Schupp, J., \& Wagner, G. (2007). Computation of standard values for physical and mental health scale scores using the SOEP version of SF-12v2. Schmollers Jahrbuch, 127(1), 171-182.

Bang, H. \& Robins, J. (2005). Doubly robust estimation in missing data and causal inference models. Biometrics, 61(4), 962-972.

Blundell, R., Dearden, L., \& Sianesi, B. (2005). Evaluating the effect of education on earnings: Models, methods and results from the National Child Development Survey. Journal of the Royal Statistical Society: Series A, 168(3), 473-512.

Böckerman, P. \& Ilmakunnas, P. (2009). Unemployment and self-assessed health: Evidence from panel data. Health Economics, 18(2), 161-179.

Browning, M., Dano, A. M., \& Heinesen, E. (2006). Job displacement and stress-related health outcomes. Health Economics, 15(10), 1061-1075.

Caliendo, M. \& Kopeinig, S. (2008). Some practical guidance for the implementation of propensity score matching. Journal of Economic Surveys, 22(1), 31-72.

Caliendo, M. \& Lee, W.-S. (2011). Fat chance! Obesity and the transition from unemployment to employment. IZA Discussion Paper, 5795.

Caliendo, M., Tatsiramos, K., \& Uhlendorff, A. (2009). Benefit duration, unemployment duration and job match quality: A regression-discontinuity approach. IZA Discussion Paper, 4670.

Cawley, J. \& Ruhm, C. J. (2011). The economics of risky health behaviors. IZA Discussion Paper, 5728.

Charles, K. K. \& Stephens, M. (2004). Job displacement, disability, and divorce. Journal of Labor Economics, 22(2), 489-522.

Cutler, D. M. \& Lleras-Muney, A. (2010). Understanding differences in health behaviors by education. Journal of Health Economics, 29(1), 1-28. 
Deb, P., Gallo, W. T., Ayyagari, P., Fletcher, J. M., \& Sindelar, J. L. (2011). The effect of job loss on overweight and drinking. Journal of Health Economics, 30(2), 317-327.

DeCicca, P., Kenkel, D., \& Mathios, A. (2008). Cigarette taxes and the transition from youth to adult smoking: Smoking initiation, cessation, and participation. Journal of Health Economics, 27(4), 904-917.

DeCicca, P. \& McLeod, L. (2008). Cigarette taxes and older adult smoking: Evidence from recent large tax increases. Journal of Health Economics, 27(4), 918-929.

Dehejia, R. \& Lleras-Muney, A. (2004). Booms, busts, and babies' health. Quarterly Journal of Economics, 119(3), 1091-1130.

Del Bono, E., Weber, A., \& Winter-Ebmer, R. (2012). Clash of career and family: Fertility decisions after job displacement. Journal of the European Economic Association, (forthcoming).

Dorsett, R. (2010). Adjusting for nonignorable sample attrition using survey substitutes identified by propensity score matching: An empirical investigation using labour market data. Journal of Official Statistics, 26(1), 105-125.

Eliason, M. \& Storrie, D. (2009). Does job loss shorten life? Journal of Human Resources, 44(2), 277-302.

Falba, T., Teng, H., Sindelar, J. L., \& Gallo, W. T. (2005). The effect of involuntary job loss on smoking intensity and relapse. Addiction, 100(9), 1330-1339.

Heckman, J., Ichimura, H., \& Todd, P. E. (1997). Matching as an econometric evaluation estimator: Evidence from evaluating a job training programme. The Review of Economic Studies, 64(4), 605-654.

Henkel, D. (2011). Unemployment and substance use: A review of the literature (19902010). Current Drug Abuse Reviews, 4(1), 4-27.

Ho, D. E., Imai, K., King, G., \& Stuart, E. A. (2006). Matching as nonparametric preprocessing for reducing model dependence in parametric causal inference. Political Analysis, 15(3), 199-236.

Jacobson, L. S., LaLonde, R. J., \& Sullivan, D. G. (1993). Earnings losses of displaced workers. American Economic Review, 83, 685-709.

Kassel, J. D., Stroud, L. R., \& Paronis, C. A. (2003). Smoking, stress, and negative affect: Correlation, causation, and context across stages of smoking. Psychological Bulletin, 129(2), 270-304.

Kassenboehmer, S. C. \& Haisken-DeNew, J. P. (2009). You're fired! The causal negative effect of entry unemployment on life satisfaction. The Economic Journal, 119(536), 448-462. 
Kletzer, L. G. (1998). Job displacement. Journal of Economic Perspectives, 12(1), $115-136$.

Kuhn, A., Lalive, R., \& Zweimüller, J. (2009). The public health costs of job loss. Journal of Health Economics, 28(6), 1099-1115.

Lechner, M. (1999). Identification and estimation of causal effects of multiple treatments under the conditional independence assumption. IZA Discussion Paper, 91.

Lechner, M. (2002). Program heterogeneity and propensity score matching: An application to the evaluation of active labor market policies. Review of Economics and Statistics, 84(2), 205-220.

Leuven, E. \& Sianesi, B. (2003). psmatch2. STATA module to perform full Mahalanobis and propensity score matching, common support graphing, and covariate imbalance testing. http://ideas.repec.org/c/boc/bocode/s432001.html. This version 4.0.4.

Lindo, J. (2011). Parental job loss and infant health. Journal of Health Economics, 20(5), 869-879.

Montgomery, S., Cook, D., Bartley, M., \& Wadsworth, M. (1998). Unemployment, cigarette smoking, alcohol consumption and body weight in young British men. The European Journal of Public Health, 8(1), 21-27.

Morgan, S. L. \& Harding, D. J. (2006). Matching estimators of causal effects: Prospects and pitfalls in theory and practice. Sociological Methods \& Research, 35(1), 3-60.

Morris, J. K., Cook, D., \& Shaper, A. G. (1992). Non-employment and changes in smoking, drinking, and body weight. British Medical Journal, 304, 536-41.

Reichert, A. \& Tauchmann, H. (2011). The causal impact of fear of unemployment on psychological health. Ruhr Economic Papers, 266.

Roelfs, D. J., Shor, E., Davidson, K. W., \& Schwartz, J. E. (2011). Losing life and livelihood: A systematic review and meta-analysis of unemployment and all-cause mortality. Social Science 85 Medicine, 72(6), 840-854.

Rosenbaum, P. R. \& Rubin, D. B. (1985a). Constructing a control group using multivariate matched sampling methods that incorporate the propensity score. American Statistician, 39, 33-38.

Rosenbaum, P. R. \& Rubin, D. B. (1985b). The bias due to incomplete matching. Biometrics, 41(1), 103-116.

Ruhm, C. J. (2000). Are recessions good for your health? Quarterly Journal of Economics, 115(2), 617-650.

Ruhm, C. J. (2005). Healthy living in hard times. Journal of Health Economics, 24(2), $341-363$. 
Ruhm, C. J. \& Black, W. E. (2002). Does drinking really decrease in bad times? Journal of Health Economics, 21(4), 659-678.

Salm, M. (2009). Does job loss cause ill health? Health Economics, 18(9), 1075-1089.

Schmitz, H. (2011). Why are the unemployed in worse health? The causal effect of unemployment on health. Labour Economics, 18(1), 71-78.

Schunck, R. \& Rogge, B. G. (2010). Unemployment and its association with healthrelevant actions: Investigating the role of time perspective with German census data. International Journal of Public Health, 55(4), 271-278.

Smith, J. A. \& Todd, P. E. (2005). Does matching overcome LaLonde's critique of nonexperimental estimators? Journal of Econometrics, 125(1-2), 305-353.

Stephens, M. (2004). Job loss expectations, realizations, and household consumption behavior. Review of Economics and Statistics, 86(1), 253-269.

Stevens, A. H. (1997). Persistent effects of job displacement: The importance of multiple job losses. Journal of Labor Economics, 15(1), 165-188.

Stuart, E. A. (2010). Matching methods for causal inference: A review and a look forward. Statistical Science, 25(1), 1-21.

Sullivan, D. G. \& Wachter, T. (2009). Job displacement and mortality: An analysis using administrative data. Quarterly Journal of Economics, 124(3), 1265-1306.

Todd, P. E. (2008). Matching estimators. In S. Durlauf \& L. Blume (Eds.), The New Palgrave Dictionary of Economics. New York: Palgrave Macmillan, 2nd edition.

Wagner, G. G., Frick, J. R., \& Schupp, J. (2007). The German Socio-Economic Panel Study (SOEP) - Scope, evolution and enhancements. Schmollers Jahrbuch, 127(1), 139-169.

World Health Organization (2009). Global health risks: Mortality and burden of disease attributable to selected major risks. Geneve: WHO Press.

Ziebarth, N. R. \& Grabka, M. M. (2009). In vino pecunia? The association between beverage-specific drinking behavior and wages. Journal of Labor Research, 30(3), 219-244. 